This article was downloaded by: [Utah State University]

On: 9 December 2010

Access details: Access Details: [subscription number 918295146]

Publisher Routledge

Informa Ltd Registered in England and Wales Registered Number: 1072954 Registered office: Mortimer House, 3741 Mortimer Street, London W1T 3JH, UK

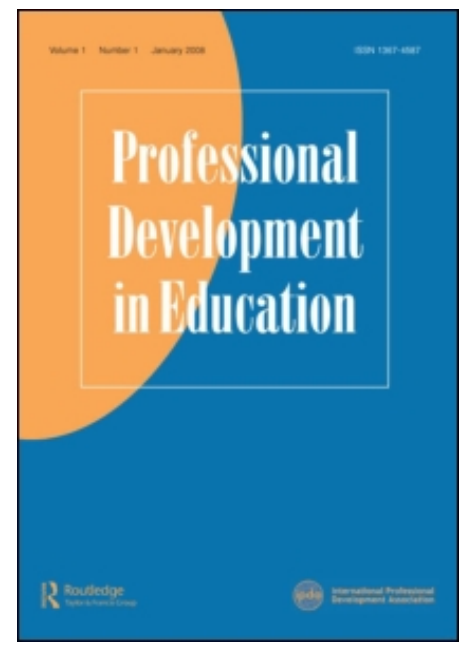

\title{
Professional Development in Education
}

Publication details, including instructions for authors and subscription information:

http://www.informaworld.com/smpp/title content=t716100715

\section{Common features of professional development activities for mathematics} and science teachers

Patricia S. Moyer-Packenham ${ }^{\mathrm{a}}$; Johnna J. Bolyard ${ }^{\mathrm{b}}$; Hana $\mathrm{Oh}^{\mathrm{c}}$; Nancy Irby Cerar ${ }^{\mathrm{c}}$

${ }^{a}$ College of Education and Human Services, Utah State University, Logan, UT, USA ${ }^{\mathrm{b}}$ West Virginia

University, Morgantown, WV, USA ${ }^{c}$ George Mason University, Fairfax, VA, USA

First published on: 07 December 2010

To cite this Article Moyer-Packenham, Patricia S. , Bolyard, Johnna J., Oh, Hana and Cerar, Nancy Irby(2010) 'Common features of professional development activities for mathematics and science teachers', Professional Development in Education,, First published on: 07 December 2010 (iFirst)

To link to this Article: DOI: 10.1080/19415257.2010.531597

URL: http://dx.doi.org/10.1080/19415257.2010.531597

\section{PLEASE SCROLL DOWN FOR ARTICLE}

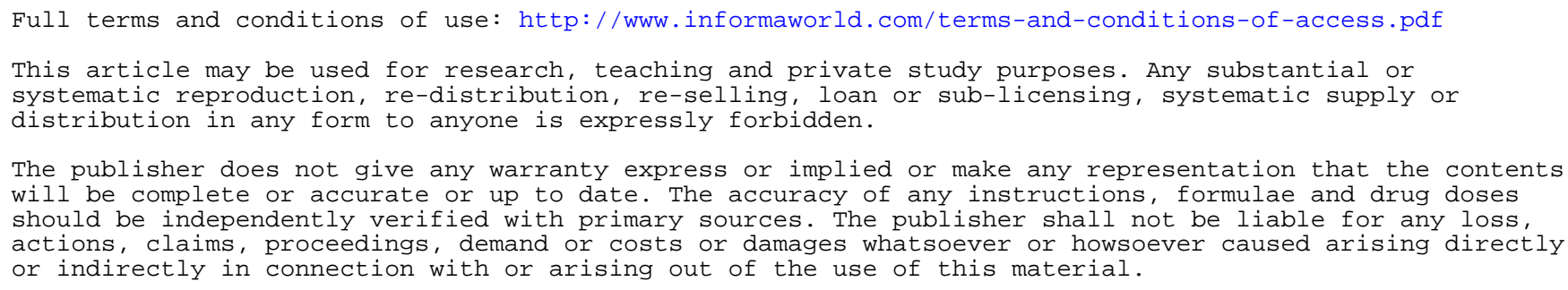




\title{
Common features of professional development activities for mathematics and science teachers
}

\author{
Patricia S. Moyer-Packenham ${ }^{\mathrm{a} *}$, Johnna J. Bolyard ${ }^{\mathrm{b}}$, Hana $\mathrm{Oh}^{\mathrm{c}}$ and Nancy Irby Cerar ${ }^{\mathrm{c}}$ \\ ${ }^{a}$ College of Education and Human Services, Utah State University, 2805 Old Main Hill, Logan, \\ UT 84341, USA; ${ }^{b}$ West Virginia University, Morgantown, WV 26506, USA; ${ }^{c}$ George Mason \\ University, Fairfax, VA 22030, USA
}

(Received 8 December 2009; final version received 1 October 2010)

This study examines professional development activities provided for mathematics and science teachers in the National Science Foundation's Math and Science Partnership Program by analyzing a cross-sectional sample of over 2000 professional development (PD) activities in the program. Data were gathered from secondary source documents and surveys to examine core and structural features of professional development offerings (i.e. form, collective participation, content, duration and outcomes). The results from this sample of PD activities for mathematics and science teachers were mixed. There was evidence of researchbased practices, including the collective participation by teachers at the same grade levels, a focus on content-specific training and sufficient duration. However, courses and workshops continued as the dominant form of PD delivery, there are few measures used to assess the PD activities, and the partnerships did not connect PD efforts for mathematics and science teachers with classroom practices and student achievement outcomes. These findings indicate that the delivery of PD has adopted important research-based strategies, but that the partnerships need to design better methods for documenting growth in teacher knowledge and connecting that growth with student outcomes.

Keywords: professional development; Math and Science Partnership Program; mathematics teacher development; science teacher development

\section{Introduction}

Over the past decade the design of professional development (PD) has become more purposeful, with a focus on using teacher PD models with demonstrated effectiveness (Blank and Alas 2008, Desimone 2009, Wei et al. 2009), and on connecting effective teacher PD models with student achievement (Craig 2006, US Department of Education 2008). The research on PD in mathematics and science indicates that there are core and structural features that have positive effects on teachers' knowledge and classroom teaching practices (Garet et al. 2001, Desimone 2009). The inclusion of these features in the design and implementation of PD for mathematics and science teachers maximizes the potential for positive effects on teachers and classrooms.

The purpose of this study was to examine the inclusion of research-based features in PD activities designed and delivered by partnerships in the National Science Foundation's Math and Science Partnership (NSF MSP) program. In particular, we were interested in determining the extent to which MSPs in the program implemented the core features (content, coherence and active learning) and structural features (form,

*Corresponding author. Email: patricia.moyer-packenham@usu.edu 
duration and collective participation) shown to have significant positive effects on teacher knowledge and classroom practice (Garet et al. 2001, Desimone 2009). Results of research on these core and structural features indicate positive effects when there is a greater emphasis on developing teachers' mathematics and science content knowledge, opportunities for active learning and coherence of the planned activities, and PD experiences of longer duration with collective participation (i.e. groups of teachers from the same school, department, or grade level) (Porter et al. 2000, Garet et al. 2001).

\section{Professional development effects on teacher knowledge, skills and practice}

$\mathrm{PD}$ is an integral part of reform efforts in mathematics and science education (Desimone et al. 2007, Blank and Alas 2008). A review of how the education system in the United States compared with those of other Group of Eight (G8) countries reveals that more teachers of US fourth-graders reported participating in PD focused on mathematics content, the improvement of students' critical thinking skills and student assessment than those of fourth-grade students in Japan, Italy and Scotland (Miller et al. 2007).

Several features have been identified as characteristics of high-quality PD and proposed as part of a 'core conceptual framework' by Desimone (2009, p. 185). One feature is the duration of PD experiences. In order for PD to be effective, teachers must have adequate time for reflection and learning (Marx et al. 1998, Speck 2002), including adequate contact hours and sustained experiences for an extended period of time (Loucks-Horsley 1998, Hiebert 1999). This allows teachers to examine their existing beliefs and reflect on new ideas (Klentschy 2005). Another recommended feature is that PD experiences be collaborative and include support from colleagues and outside experts (Briscoe 1991, Marx et al. 1998, Lee 2004/05). Further, PD should provide opportunities for active participation in learning (Marx et al. 1998), should be based on participants' needs and goals (Lee 2004/05, Klentschy 2005) and should be grounded in teachers' work (Speck 2002).

Several large-scale reviews of effective PD in mathematics and science echo these recommendations (Desimone et al. 2002, Peck et al. 2007, Blank and Alas 2008, Bolyard and Moyer-Packenham 2008, Desimone 2009). These reviews emphasize the importance of the frequency and duration of the experiences, a focus on mathematics and science content, and methods for assessing the quality of the PD experiences. Other recommendations include an emphasis on encompassing multiple elements of the system (Loucks-Horsley 1998), opportunities for teacher leadership (Desimone et al. 2002), and improved measures and methods for studying the effects of PD on teachers and students (Blank and Alas 2008, Desimone 2009).

Many of these recommendations are characteristic of what Moyer-Packenham and Westenskow (in press) refer to as content-embedded PD, where the learning of mathematics and science content is embedded within the activity rather than being the sole goal of the activity (Desimone 2009, Wei et al. 2009). Examples of content-embedded PD might include lesson study (Fernandez 2005, Lewis et al. 2006), peer or content coaching (Feger et al. 2004), mentoring (Halai 1998, Pourdavood et al. 1999), teacher research (Edwards and Hensien 1999) and professional learning communities (Arbaugh 2003, Snow-Gerono 2005). By nature, these experiences are longer term, are teacher driven, encourage active participation and collaboration, and are more coherent with the work of teaching. However, Wei et al. note that, 'Overall, the kind 
of high-intensity, job-embedded collaborative learning that is most effective is not a common feature of PD across most states, districts, and schools in the United States' (Wei et al. 2009, p. 4). This trend occurs not only in the United States, but elsewhere; as Boyle and Lamprianou (2006) note, the participation of primary and secondary teachers in England in these types of embedded PD offerings has increased over time.

Results on the use of lesson study to increase teachers' mathematics and science knowledge are reported for teachers in different countries. Fernandez $(2002,2005)$ found that the use of lesson study with a group of elementary teachers from the United States served as an incentive for teachers to learn more content. Marsigit (2007) found that participation in lesson study improved Indonesian secondary mathematics teachers' instructional practices and skills. Marble (2007), likewise, found participation in lesson study to lead to improvements in pre-service elementary teachers' skills for science instruction.

A direct goal of PD is to impact teachers' knowledge, beliefs, skills and, ultimately, their practice. For example, Hill and Ball (2004) found that participation in a PD program focused on mathematics content improved teachers' performance on measures of mathematical knowledge for teaching. Other features related to teacher knowledge growth included the length of the program and opportunities for active learning. Using data from the 2000 National Assessment of Educational Progress Mathematics Assessment eighth-grade sample, Smith et al. (2005) found a relationship between teachers' participation in content-focused PD and their reported emphasis on conceptual learning goals and instructional strategies. Other studies have found positive impacts of professional development experiences based on curriculum materials. Collopy (2003) conducted a case study of two elementary teachers' learning through the use of mathematics curriculum materials and found that one teacher demonstrated marked changes in her instructional philosophy and practices.

Some findings suggest positive effects of PD when experiences are closely tied to teachers' work and goals, and involve collaboration among colleagues and experts. Two studies (Blank et al. 2006, Porter et al. 2007) that examined the impact of a program using data on teachers' instructional practices and student achievement to design PD experiences found that all schools in the study developed greater alignment of instruction with mathematics and science standards.

Experiences that foster collaboration among colleagues and experts have also been reported to positively influence teachers' knowledge, practice and beliefs. Edwards and Hensien (1999) found that elements of collaboration, support and reflection inherent in a collaborative action research effort between a middle school mathematics teacher and a mathematics teacher educator contributed to changes in the teacher's knowledge, beliefs and practices. Lieberman (2009) found mathematics teachers' participation in lesson study facilitated the development of a learning community. Nelson and Slavit (2007) examined case studies of Grades 6-12 science and mathematics teachers engaged in collaborative inquiry and found that the collaborative inquiry contributed to their professional growth.

Explicit modeling of desired instructional practices has been documented as positively influencing teacher outcomes. Clark et al. (2008) found that secondary mathematics and science teachers' concurrent participation in a course and professional learning community experiences supported the emergence of participants' use of conceptually based descriptions about solution approaches. This emergence resulted from experts' modeling and reinforcing these behaviors with participants. 
Hanegan et al. (2009) found that students of teachers who had participated in a PD experience that modeled authentic inquiry teaching in science asked more openended, higher-order questions than students of teachers who participated in a PD experience modeling simulated inquiry. Finally, elementary teachers' participation in discussions of discourse structures in inquiry-based science instruction deepened participants' understanding of their and their students' social roles, facilitating a connection between theory and practice (Oliveira 2010). The PD experiences were facilitated by experts in both science content and discourse.

\section{Professional development and connections to student outcomes}

Desimone (2009) proposes a core conceptual framework for connecting the effects of PD with students and teachers. This core conceptual framework links core features of PD with increased teacher knowledge, changes in instruction and improved student achievement. Although it is difficult to find large-scale research that explicitly links PD with changes in student achievement, recent reports do show that it is possible to isolate and measure the effects of PD features on student achievement (Garet et al. 2008, Glazerman et al. 2008). Kennedy's (1998, 1999) earlier reviews of studies of PD that examined student outcomes in mathematics and science indicated that the content of PD programs was important in predicting benefits to students. For example, mathematics PD programs that focus on knowledge of subject and how students learn the subject have greater effects on students. In science, the review suggests that content also matters. To date, the most consistent positive link between teachers' subject specific preparation and student achievement occurs in secondary mathematics (Goldhaber and Brewer 2000, Telese 2008).

Additionally, there have been small-scale studies relating PD to student outcomes, specifically focusing on teachers' understanding of content and students' learning of content. For example, Fennema et al. (1996) found substantial changes in the instruction of 18 teachers that were related to changes in student achievement in a study of 21 primary grade teachers. Cobb et al. (1991) studied 10 second-grade classrooms and found higher levels of conceptual understanding and computational skills in the project classes versus the non-project classes. Lewis et al. (2006) found evidence of a positive impact on students' mathematics achievement scores when lesson study was used as a PD model.

In the present study, we examine the inclusion of those research-based features shown to positively affect teacher knowledge and instructional practices in the PD activities designed and delivered by partnerships in the NSF MSP program. The following research questions sought to determine the extent to which MSPs in the program implemented the core features (content, coherence and active learning) and structural features (form, duration and collective participation) shown to have significant positive effects on teacher knowledge and classroom practice (Garet et al. 2001, Desimone 2009). In the MSP program: What are the most common forms of the teacher PD activities (e.g. courses, institutes, workshops)?; What is the collective participation of the teachers in the PD activities (e.g. grade level)?; What are the most common content foci of the teacher PD activities (e.g. mathematics and science standards and topics)?; What are the most common durations of teacher PD activities (e.g. hours, days, weeks)?; and How are the outcomes of teacher PD activities documented and measured? These questions sought to illuminate, through a descriptive analysis, the inclusion of effective features in the PD activities of partnerships in the NSF MSP Program. 


\section{Methods}

\section{Data sources}

The present study used data from the NSF MSP Program. We analyzed a crosssectional sample of qualitative and quantitative sources to triangulate findings. Data were gathered from $48 \mathrm{NSF}^{\mathrm{MSPs}}{ }^{1}$ (ongoing at the time of data collection and analysis) awarded during FY2002-2004. The projects were in their second, third or fourth year of administration at the time of our analysis.

\section{Qualitative measures}

The first source of data was in the form of annual and evaluation reports. These selfreport documents were submitted annually by the MSPs to the NSF to report yearly progress. We reviewed a total of 108 report documents: 22 reports from Year 1 (20032005), 34 reports from Year 2 (2004-2006), 41 reports from Year 3 (2005-2007) and 11 reports from Year 4 (2006-2008). There were 48 annual reports reviewed, one from each of the 48 MSPs. There were 60 evaluation reports reviewed, with two evaluation reports each from 16 of the MSPs, one evaluation report each from 28 of the MSPs and four MSPs where an Evaluation report was not reviewed. All 48 of the MSPs were represented in the sample. These reports represented a purposive cross-section sample of the documents describing the PD activities offered by the MSPs.

\section{Quantitative measures}

The second source of data was obtained from three surveys in the NSF MSP Management Information System (MIS). The three surveys were entitled Annual Institution of Higher Education Survey, Annual K-12 District Survey and Annual Survey for Comprehensive and Targeted Partnership Projects. These surveys provided numerical data on the PD activities of the MSPs since their inception. The data include two annual survey administrations, with 34 MSPs completing the surveys during the first administration and 40 MSPs completing the surveys during the second administration. (We will refer to these survey administrations as Wave I and Wave II.) Specific responses were extracted from the surveys that focused on pre-service and in-service teacher PD activities, including the development of courses and programs for teachers, numbers of participants in PD activities, specific groups participating in the activities, the duration of the activities and the content focus of the activities.

\section{Procedures}

We developed a reader protocol, based on PD features described by Garet et al. (2001), to conduct the document analysis. The protocol focused on identifying structural features (form, duration and collective participation) and core features (content, coherence and active learning) (Garet et al. 2001).

\section{Structural features}

Garet et al. (2001) describe form as the type of PD activity, including learning communities, study groups, lesson study, workshops, courses and institutes. They 
describe duration as the total number of contact hours and the span (in days, weeks and months) of the PD activity. In our results, we converted all units of length into hours for ease of comparison. Some items could not be converted (e.g. reports that stated 'daily', 'weekly' or 'regularly'). Collective participation refers to groups of teachers from the same school, department or grade level participating together in PD (Garet et al. 2001). We categorized collective participation by: groups of teachers from the same grade levels; groups of teacher leaders; and groups of pre-service teachers participating in the PD.

Core feature. The core feature identified by Garet et al. (2001) and included in our analysis was content. This category included information that was presented during the PD activity, such as mathematics and science content, teaching practices, lesson planning, curriculum materials or other instructional content (Garet et al. 2001). We first categorized PD activities as being mathematics-focused, science-focused or mathematics and science-focused. These were further categorized into sub-categories based on the National Council of Teachers of Mathematics (2000) content standards and the National Science Education Standards (National Research Council 1996). These sub-categories were coded by mathematics and science content experts.

We identified two additional features that focused on outcomes: instruments and benchmarks. We identified instruments being used by the MSPs to document teacher PD outcomes and benchmarks related to the PD goals of the project. In our results, we report items for most categories when they reached a minimum frequency of $2.5 \%$ among all of the PD activities. Those items that appeared in less than $2.5 \%$ of activities, or those that lacked sufficient detail to determine their form, were grouped in an other category.

\section{Analysis}

We identified information from the documents in multiple phases. First, we read and extracted information from the reports. We then used keywords to search all of the documents. Next, we organized this information by features of PD. During these phases we repeatedly reviewed the narrative documents to identify additional information until we reached data saturation. To triangulate data obtained from the narrative documents, we compared these data with numerical data from the MSP MIS survey items. MSP MIS survey data provided information on courses and programs developed or offered by the MSPs, the duration of PD activities, numbers and types of participants in those activities, and numbers of PD activities. To present our results, we converted information extracted from the narrative reports into a numeric format for each of the six features, using frequencies and percentages for ease of comparison. Items were weighted in the analysis so that each individual PD activity maintained a total weight of 1.0 .

\section{Results}

The following results illuminate the inclusion of research-based features of PD provided for mathematics and science teachers in the MSP program. The results examine the six core and structural features being implemented by these partnerships. The 
tables primarily display those categories that were identified in at least $2.5 \%$ of the PD activities, with information on the other categories included in the text.

\section{Our sample}

During the first part of our analysis, we identified the number of participants in the PD activities in the 48 MSPs. The MSP MIS data indicated that there were 34,004 teachers at the K-12 level that received PD (based on Wave II data, Annual $\mathrm{K}-12$ District Survey). This included 21,041 elementary school teachers, 6680 middle school teachers (3929 mathematics and 2751 science) and 6283 high school teachers (3696 mathematics and 2587 science). Elementary school teachers represented the largest group participating in PD (61.9\% of all participants), followed by middle school teachers $(19.6 \%)$ and high school teachers (18.5\%). More mathematics teachers in middle and high school participated in PD activities than science teachers $(7625$ and 5338, respectively). At the post-secondary level, a total of 9790 individuals enrolled in institutions of higher education (including science, technology, engineering, and mathematics undergraduates, pre-service undergraduates, alternative certification students, graduate students and postdoctoral students) and were recipients of PD. A total of 16,800 course enrollments were reported for pre-service students during these academic years. These data identify the scope of individuals with which the partnerships worked.

The surveys and narrative reports revealed a discrepant total number of PD activities. The Annual Survey for Comprehensive and Targeted Partnership Projects (Waves I and II) reported 1481 separate PD activities; and the annual reports identified 2340 separate PD activities. The discrepancy in the number of PD activities was caused by several factors. The survey data included 40 MSPs, while the report data included 48 MSPs; therefore, there were more MSPs included in the data from the reports. The MSP MIS survey data were reported by MSPs prior to many of the partnerships writing their third-year and fourth-year reports; therefore, there were additional activities included in the reports that were under-reported on the surveys. Finally, some MSPs did not provide information on the surveys detailing all of their PD activities, even though they described these activities in their reports. Essentially, they under-reported their activities on the surveys. The narrative reports provided much greater description of the features of the PD activities; therefore, the results in the sections that follow are based on the 2340 PD activities described in the narrative reports.

\section{Results based on the six features of professional development}

\section{Forms of professional development}

The first research question we examined was: What are the most common forms of the teacher PD activities (e.g. courses, institutes, workshops) in the MSP program? In the reports, a total of 1605 of the $2340 \mathrm{PD}$ activities in mathematics and science identified the form of the PD. Table 1 shows the most common forms that were identified. These included courses (30.0\%), workshops (20.2\%), institutes (13.1\%) and meetings $(10.6 \%)$. Those forms reported with less frequency included trainings $(9.0 \%)$, programs $(7.9 \%)$, conferences $(5.3 \%)$ and seminars $(3.9 \%)$. Of the 2340 PD activities identified, $735(31.4 \%)$ did not identify a specific form or identified in a form category 
Table 1. Form of teacher professional development activities.

\begin{tabular}{lc}
\hline Form & Identified frequency $(n=1605)$ \\
\hline Course & $481(30.0 \%)$ \\
Workshop & $325(20.2 \%)$ \\
Institute & $210(13.1 \%)$ \\
Meeting & $170(10.6 \%)$ \\
Training & $145(9.0 \%)$ \\
Program & $126(7.9 \%)$ \\
Conference & $85(5.3 \%)$ \\
Seminar & $63(3.9 \%)$ \\
\hline
\end{tabular}

Notes: 108 MSP annual and evaluation reports; 735 out of 2340 PD activities (31\%) did not identify the form of the activity, or the form was identified and did not meet the minimum frequency of $2.5 \%$ for inclusion in the identified form categories.

that did not reach a minimum frequency of $2.5 \%$. Some of these PD activities included study groups, teacher collaborations, teacher networks, mentoring/coaching, internships, learning communities and lesson study. Courses, workshops and institutes continued to be the most common forms of teacher PD, even though research-based findings indicate that the more effective forms are those that were offered less frequently among the partnerships.

The surveys showed that a total of 82 new courses, 179 modified courses, 11 other courses and 10 new alternative certification programs were offered. While forms of PD activities, including peer coaching and study groups, were described in less than $2.5 \%$ of PD activities in the reports, the survey results showed that there was peer coaching in 19 (out of 34) MSPs and that there were study groups in 16 MSPs during Wave I. During Wave II, 20 (out of 40) MSPs reported peer coaching and 27 reported study groups on the survey. These data indicate that, although these forms occurred with less frequency among all of the activities, the forms were present in about onehalf of the MSPs across the program.

\section{Collective participation}

The next research question asked: What is the collective participation of the teachers in the PD activities? The data indicate that teachers most often participated collectively in grade-level groups, or as pre-service teachers or teacher leaders. The largest participating groups were teachers participating by specific grade levels (69.9\%), with teachers in Grades Six, Seven and Eight having the most opportunities to participate collectively. With less frequency were pre-service teachers $(16.4 \%)$, and teacher leaders $(13.7 \%)$ participating as collective groups (see Table 2 ).

\section{Content of professional development}

The next research question examined: What are the most common content foci of the teacher PD activities in the MSP program? The majority of PD activities focused on mathematics $(56.6 \%)$, followed by science $(25.0 \%)$ and combined content $(18.5 \%)$. The content foci of the PD in both mathematics and science are presented in Tables 3 
Table 2. Categories of collective participation.

\begin{tabular}{lc}
\hline Collective group & Identified frequency $(n=1113)$ \\
\hline Specific grade level & $778(69.9 \%)$ \\
Pre-service teachers & $182(16.4 \%)$ \\
Teacher leaders & $153(13.7 \%)$ \\
\hline
\end{tabular}

Notes: 108 MSP annual and evaluation reports; 1227 out of 2340 PD activities (52\%) did not identify the collective participation of the activity, or the collective participation was identified and did not meet the minimum frequency of $2.5 \%$ for inclusion in the identified collective participation categories.

Table 3. Content of mathematics-focused professional development.

\begin{tabular}{lc}
\hline & Identified frequency $(n=542.01)$ \\
\hline NCTM content standards (2000) & \\
Algebra & $88.73(16.4 \%)$ \\
Geometry & $82.65(15.2 \%)$ \\
Numbers and operations & $49.49(9.1 \%)$ \\
Data analysis and probability & $47.83(8.8 \%)$ \\
Measurement & $9.83(1.8 \%)$ \\
Curriculum & $159.08(29.4 \%)$ \\
Calculus & $29.16(5.4 \%)$ \\
Assessment & $28.58(5.3 \%)$ \\
Problem solving & $25.75(4.8 \%)$ \\
\hline
\end{tabular}

Notes: 108 MSP annual and evaluation reports; 1798 out of 2340 PD activities (77\%) did not identify the specific content focus of the mathematics activity, or the content focus was identified and did not meet the minimum frequency for inclusion in the table; $n$ values are not reported as whole numbers due to the weighting of categories within the feature.

Source: NCTM content standards from National Council of Teachers of Mathematics (2000).

and 4. (Decimal numbers in the tables are a result of the weighting system used to categorize items.) Some activities lacked specific detail and were not categorized. For example, an activity may have been described as a science-focused PD activity, but no details were provided on the specific science-related content that was addressed.

There were approximately 542 activities that included mathematics-focused content (see Table 3). The most frequent mathematics-focused content was curriculum $(29.4 \%)$, followed by algebra $(16.4 \%)$, geometry $(15.2 \%)$, number and operations $(9.1 \%)$, and data analysis and probability $(8.8 \%)$. With less frequency, the mathematics-focused PD included calculus (5.4\%), assessment (5.3\%), problemsolving (4.8\%) and measurement (1.8\%). There were approximately 293 activities that included science-focused content (see Table 4). The most frequent topic presented in the science-focused PD was physical science $(32.1 \%)$, followed by earth and space science $(20.2 \%)$, life science $(17.4 \%)$, curriculum $(11.2 \%)$ and science as inquiry $(8.3 \%)$. With less frequency the science PD included science and technology $(4.2 \%)$, unifying content and processes in science $(3.8 \%)$, and history and nature of science $(1.8 \%)$. 
Table 4. Content of science-focused professional development.

\begin{tabular}{lc}
\hline & Identified frequency $(n=292.86)$ \\
\hline NSTA content standards (1996) & \\
Physical science & $94.01(32.1 \%)$ \\
Earth and space science & $59.27(20.2 \%)$ \\
Life science & $50.94(17.4 \%)$ \\
Science as inquiry & $24.32(8.3 \%)$ \\
Science and technology & $12.32(4.2 \%)$ \\
Unifying content and processes in science & $11.26(3.8 \%)$ \\
History and nature of science & $5.33(1.8 \%)$ \\
Curriculum & $32.91(11.2 \%)$ \\
\hline
\end{tabular}

Notes: 108 MSP annual and evaluation reports; 2047 out of 2340 PD activities (87\%) did not identify the specific content focus of the science activity, or the content focus was identified and did not meet the minimum frequency for inclusion in the table; $n$ values are not reported as whole numbers due to the weighting of categories within the feature.

Source: National Science Teachers Association content standards from the National Research Council (1996).

\section{Duration of professional development}

The next research question asked: What are the most common durations of the teacher PD activities (e.g. hours, days, weeks) in the MSP program? The MSP MIS survey reported the amount of $\mathrm{PD}$ hours received by $\mathrm{K}-12$ teachers since the inception of the MSP and was organized by elementary school, middle school (subdivided by mathematics and science) and high school (subdivided by mathematics and science) teachers. There were 34,004 teachers that received PD (see Table 5). Of those teachers, the largest portion (38.9\%) participated in $21-40$ hours of PD, closely followed by $34.2 \%$ of teachers who participated in 1-20 hours of PD. A lesser number of teachers participated in 41-80 hours (14.2\%), 80-120 hours (6.3\%), 161+ hours (3.9\%) and 121-160 hours $(2.4 \%)$. These data show that the majority of teachers received between 1 and 40 hours of PD from the MSPs. Duration was also identified in the report documents (see Table 6). In 959 activities where duration was reported, 1-20 hours was the most

Table 5. Intervals of professional development hours by teacher level and content $(n=34,004$ $\mathrm{K}-12$ teachers).

\begin{tabular}{|c|c|c|c|c|c|c|}
\hline \multirow[b]{2}{*}{ Wave 2} & \multirow[b]{2}{*}{ Elementary } & \multicolumn{2}{|c|}{ Middle } & \multicolumn{2}{|c|}{ High } & \multirow[b]{2}{*}{ Total } \\
\hline & & Math & Science & Math & Science & \\
\hline 1-20 hours & 7466 (35.5) & $1323(33.7)$ & 788 (28.6) & $1305(35.3)$ & $752(29.1)$ & $11,634(34.2)$ \\
\hline $21-40$ hours & 9236 (43.9) & $1133(28.8)$ & $991(36.0)$ & $1071(30.0)$ & $810(31.3)$ & $13,241(38.9)$ \\
\hline 41-80 hours & $2328(11.1)$ & $750(19.1)$ & $506(18.4)$ & $686(18.6)$ & $562(21.7)$ & $4832(14.2)$ \\
\hline 80-120 hours & $1125(5.3)$ & $325(8.3)$ & $188(6.8)$ & $286(7.7)$ & $217(8.4)$ & $2141(6.3)$ \\
\hline $121-160$ hours & 392 (1.9) & $114(2.9)$ & $72(2.6)$ & $130(3.5)$ & $116(4.5)$ & $824(2.4)$ \\
\hline $161+$ hours & $494(2.3)$ & $284(7.2)$ & $206(7.5)$ & $218(5.9)$ & $130(5.0)$ & 1332 (3.9) \\
\hline Total & $21,041(61.9)$ & 3929 (11.6) & $2751(8.1)$ & 3696 (10.9) & 2587 (7.6) & 34,004 \\
\hline
\end{tabular}

Notes: Annual K-12 District Survey; based on Wave II data from 40 MSPs representing the total number of PD hours since the inception of the MSP program. Percentages are given in brackets. 
Table 6. Duration.

\begin{tabular}{lc}
\hline Duration & Identified frequency $(n=959)$ \\
\hline $1-20$ hours & $554(57.8 \%)$ \\
$21-40$ hours & $272(28.4 \%)$ \\
$41-80$ hours & $68(7.1 \%)$ \\
$81-120$ hours & $25(2.6 \%)$ \\
$121-160$ hours & $25(2.6 \%)$ \\
$161+$ hours & $15(1.6 \%)$
\end{tabular}

Notes: 108 MSP annual and evaluation reports; 1381 out of 2340 PD activities (59\%) did not identify the duration of the activity in a form that could be converted to hours.

frequent duration of PD activities (57.8\%), followed by 21-40 hours (28.4\%). Both the survey and report data show a consistent pattern in the number of hours of teacher participation, with 1-40 hours being the most frequent.

\section{Outcomes of professional development}

The final research question asked: How are the outcomes of teacher PD activities documented and measured in the MSP program? We examined instruments and benchmarks to determine: whether MSPs were reporting information on instruments being used to collect data on outcomes of the PD activity, and whether MSPs reported the attainment of benchmarks associated with the PD activity. There were several different instruments reported to assess teacher growth and teacher knowledge (see Table 7). The instruments most frequently used were surveys $(38.6 \%)$, followed by tests/examinations $(27.6 \%)$, observations $(21.5 \%)$, interviews (8.3\%) and portfolios $(3.9 \%)$. A large portion of activities (1862 out of 2340, 79.6\%) did not report the use of any instruments to measure PD outcomes. (For a more complete discussion of the instruments used by the MSPs, see Moyer-Packenham et al. 2008.) A total of 476 PD activities identified benchmarks, and $85.2 \%$ indicated that they met their benchmarks (see Table 8). Examples of benchmarks included recruiting a set number of participants in the PD activity, numbers of teachers completing a course and increases in student mathematics achievement in classes taught by participating teachers. However, the findings for this feature

Table 7. Instruments used during and following professional development activities.

\begin{tabular}{lc}
\hline Instrument & Identified frequency $(n=408.43)$ \\
\hline Surveys & $157.81(38.6 \%)$ \\
Tests/examinations (local and external) & $112.88(27.6 \%)$ \\
Observations & $87.74(21.5 \%)$ \\
Interviews & $33.65(8.3 \%)$ \\
Portfolios & $15.93(3.9 \%)$ \\
\hline
\end{tabular}

Notes: 108 MSP annual and evaluation reports; 1932 out of 2340 PD activities (83\%) did not identify the instruments used during the activity, or the instruments used were identified and did not meet the minimum frequency of $2.5 \%$ for inclusion in the identified instruments used categories; $n$ values are not reported as whole numbers due to the weighting of categories within the feature. 
Table 8. Benchmarks for professional development activities.

\begin{tabular}{lc}
\hline Benchmark & Identified frequency $(n=476)$ \\
\hline Met & $405.5(85.2 \%)$ \\
Not Met & $70.5(14.8 \%)$ \\
\hline
\end{tabular}

Notes: 108 MSP annual and evaluation reports; 1864 out of 2340 PD activities (80\%) did not identify whether or not the benchmark for the activity was met; $n$ values are not reported as whole numbers due to the weighting of categories within the feature.

are extremely limited due to the fact that benchmark information was not reported for 1864 of the 2340 activities $(79.7 \%)$.

\section{Discussion}

In this study we examined the inclusion of research-based design elements in the delivery of PD activities for mathematics and science teachers in the NSF MSP program, with a specific interest in determining the extent to which partnerships in the program implemented the core and structural features shown to have significant positive effects on teacher knowledge and classroom practice (Garet et al. 2001, Desimone 2009). Our results show that the partnerships have included various forms of PD, the collective participation of teachers, a content focus in their activities, with some consideration of the duration of the activities, and instruments and benchmarks used to document outcomes for over 2000 PD activities.

With regard to the first research question, focused on the most common forms of teacher PD, courses and workshops were most commonly identified. These results show that, overall, MSPs have continued a traditional model of PD delivery, rather than using more reform-oriented forms (i.e. professional learning communities or coaching) (Loucks-Horsley et al. 1998, Garet et al. 2001). In similar research, the National Center for Education Statistics (2005) found reform-oriented activities to be less common than traditional forms of PD, with $95 \%$ of teachers reporting participation in workshops, conferences or training sessions in the past 12 months, compared with $42 \%$ reporting participating in mentoring, coaching or peer observation. The findings are also consistent with a recent report by the National Staff Development Council showing that, while nine out of 10 teachers have participated in PD in the form of short-term workshops, fewer teachers have participated in extended learning and more collaborative PD opportunities (Wei et al. 2009). In addition, the US Department of Education's Mathematics and Science Partnership program (http:// www.ed-msp.net/) has similarly reported that summer institutes and in-school follow-up activities are the primary methods of mathematics and science teacher PD, with reform-oriented methods offered less frequently (US Department of Education 2008).

More reform-oriented forms of $\mathrm{PD}$, such as peer coaching and study groups, were present among the MSPs, but with less frequency. One possible explanation for this is that reform-oriented activities could be closely linked with other activities, and therefore embedded in other PD offerings (Wei et al. 2009, Moyer-Packenham and Westenskow in press). For example, a peer coach might be conducting workshops and seminars for teachers in a school or district as ongoing PD throughout the academic year. In fact, the narrative reports reveal that many of the MSPs employ 'train the 
trainer' models, where teacher leaders often work with their own schools to provide ongoing PD for teachers on site throughout the academic year. Therefore, while peer coaching might be mentioned as a single activity, it could be connected with multiple PD efforts. In addition, reform-oriented PD often does not follow a quantifiable structure. In many cases, reform-oriented PD has an ongoing structure. For example, coaching teachers or participating in a learning community is an ongoing activity that could cross content areas, could change in terms of participation of individuals at any given time, and could have a more flexible duration schedule than traditional PD activity. Therefore, reform-oriented activities may not be easily quantified and reported as separate activities. Moyer-Packenham and Westenskow (in press) also point out the challenge for evaluators trying to assess growth in teachers' content knowledge when the content is embedded within other development activities. New metrics will need to be developed to determine teacher knowledge growth within these new research-based reform-oriented PD structures.

The results on collective participation showed that the largest portion of PD activities focused on a specific grade level or focused on a specific group, such as preservice teachers or teacher leaders. Research suggests that when teachers participate collectively they are more likely to have opportunities to discuss concepts and skills in relation to their particular school, department or grade level (Garet et al. 2001). According to the results, this sample of PD activities shows that MSPs have adopted a model that allows teacher participants to better integrate what they are learning into their teaching because the learning is more contextualized to their specific grade level (Loucks-Horsley et al. 1998). This was particularly true for teachers in Grades Six, Seven and Eight, who had more opportunities to participate collectively. The PD of middle-grade teachers is particularly important for a variety of reasons. Recent analyses of Trends in International Mathematics and Science Study (TIMSS) data indicate that, in comparison with other top-performing countries, the middle school mathematics curriculum in the United States is not particularly demanding (Schmidt et al. 2002). The middle grades often have teachers in positions where they are teaching out of their field of licensure or degree (i.e. an elementary-certified teacher teaching eighth-grade algebra or physical science). The efforts by the MSPs to provide PD training for inservice and pre-service teachers in the middle grades represent an understanding of this critical need for teacher development for middle school teachers. The MSPs also focused attention on training teacher leaders, which builds capacity in school districts so that, long term, schools will have a cadre of experts who can continue the initiatives when MSP funding ends (Smylie 1995, 1996, York-Barr and Duke 2004).

The results focusing on the most common content delivered as part of teacher PD showed that over one-half of the activities focused on mathematics, with about a quarter focused on science. This finding could be a reflection of the large number of projects in the MSP portfolio that are focused on mathematics only or mathematics and science combined. Additionally, the No Child Left Behind Act of 2001, holding districts accountable for reading and mathematics scores, could account for the strong emphasis on mathematics across the program. Regardless of the content selection, the focus on content-specific PD shows the MSPs implementing the suggestions from research on the importance of content development in the design of activities for mathematics and science teachers (Garet et al. 2001).

Among the mathematics-focused PD activities, mathematics curriculum was the most common topic covered (approximately $30 \%$ of the PD activities), as compared 
with the science-focused PD, where science curriculum received less emphasis (approximately 11\%). The greater emphasis on curriculum in the mathematics-focused content, as compared with the science-focused content, may have been due to the availability of NSF-funded curriculum materials developed for mathematics in the past two decades. The creation of these materials was part of a major curriculum and implementation effort designed to improve mathematics instruction (Senk and Thompson 2003, National Research Council 2004).

In the mathematics-focused $\mathrm{PD}$, the content topic to receive the greatest attention in this sample was algebra. This is a critical focus area in light of recent reports. While other countries' middle school curriculum shifts from a focus on arithmetic to beginning algebra and geometry concepts, the US curriculum remains fragmented and widely varied. The largest proportion of US eighth-graders are enrolled in a regular mathematics course rather than a course in pre-algebra or higher, and almost one-third of US students do not attend schools where algebra is offered (Cogan et al. 2001). In the science-focused PD the most common content presented was physical science, followed by earth and space science and life science. The results for both mathematics and science indicate that teachers learning content or improving their knowledge of content was a primary focus of MSPsupported teacher PD activities. This focus on content demonstrates that the MSPs understand the importance of improving teachers' content knowledge as a major factor in improving students' content knowledge in mathematics and science. Particularly for mathematics, this is the strongest link in the research to improving student achievement outcomes.

The most common durations of teacher PD activities were between one hour and 40 hours of PD. By comparison, in a general sample of public school teachers' participation in PD hours, the teachers in these partnerships have participated in a greater number of PD hours overall (National Center for Education Statistics 2005). For example, regardless of content, a majority of teachers, in general, have received eight or fewer hours of PD in the previous year (National Center for Education Statistics 2005), while the teachers in the present sample have received between one hour and 40 hours of PD. It is also important to highlight that between $14 \%$ and $25 \%$ of teachers in the present sample have received more than 40 hours of PD since the inception of the MSP program, and even more impressive are the $7-12 \%$ of MSP teachers who have received over 80 hours of PD. As our results showed, elementary school teachers represented the largest portion of $\mathrm{PD}$ activity recipients.

\section{Observations}

Results from our review of over 34,000 teachers are similar to those of the National Center for Education Statistics (2005) survey of 44,933 public school teachers, which found that elementary teachers reported participation in more PD in content and methods than secondary teachers. The results also indicate that there were a large number of pre-service students participating in MSP-supported courses and seminars. Regardless, these results show that MSP-supported activities reached a large number of teachers in pre-licensure populations. Although these results show large-scale participation by teachers in PD activities, they are not accompanied by large-scale analyses of teacher knowledge development or links to student achievement in mathematics and science. Further PD designs must go beyond the simple documentation 
of participation hours, and include plans for documenting teacher and student growth based on the content of the PD.

Finally, in terms of documenting and measuring PD activities, the results are very limited. While surveys and examinations were reported as ways to measure the results of PD efforts, they are identified in very few PD activities in this sample. Additionally, most MSPs did not report benchmark information for the PD activities; although those that did reported that they met their benchmarks. Prior research on the activities of the MSPs has indicated that, when different types of instruments were used to measure teacher content knowledge after participating in PD activities, there was a significant effect for the use of standard content tests or examinations to measure growth in teachers' mathematics and science content knowledge when compared with other possible measurement instruments (Moyer-Packenham et al. 2008, Moyer-Packenham and Westenskow in press). Therefore, while the findings indicate that the delivery of PD has adopted important research-based strategies for delivery, partnerships need to design better methods for documenting growth in teacher knowledge and connecting that growth with student outcomes.

Overall, our findings on the inclusion of research-based design elements in the delivery of PD activities for mathematics and science teachers in the NSF MSP program are mixed. There are practices occurring that demonstrate the implementation of research-based, effective PD for mathematics and science teachers. The positive elements in the design of PD in the program show that: there is a focus on collective participation by teachers who teach at the same grade levels, the PD includes specific content such as algebra and physical science, and large portions of teachers are participating in over 20 hours of PD in mathematics and science. These findings indicate that the delivery of PD has adopted important research-proven methods. When teachers participate as a group by grade levels, they can focus on their own learning of the mathematics and science content and on how to support students' learning of that content by examining specific topics and student misconceptions and error patterns.

Conversely, traditional forms of PD are being used throughout the program, while more reform-oriented and content-embedded forms were reported less frequently. Courses and workshops continue as the dominant form of PD. Perhaps the challenge for evaluators in documenting growth in teacher content knowledge in these reformoriented and embedded forms of PD constrains designers from using them. There are also few measures used to assess the PD activities, and these assessments are rarely connected with mathematics and science teachers' classroom practices and student achievement outcomes. The alignment of all of the core and structural features with a clear design for teacher and student assessment is key to bringing together effective PD for teachers of mathematics and science and being able to document effects on teachers' knowledge growth and changes in their practices that result in improved student outcomes.

\section{Acknowledgements}

This article is one in a series of studies for the Math and Science Partnership Program Evaluation (MSP-PE) conducted for the National Science Foundation's Math and Science Partnership Program (NSF MSP). The MSP-PE is conducted under Contract No. EHR-0456995. Since 2007, Bernice Anderson, EdD, Senior Advisor for Evaluation, Directorate for Education and Human Resources, has served as the NSF Program Officer. The MSP-PE is led by COSMOS 
Corporation. Robert K. Yin (COSMOS) serves as Principal Investigator (PI). Darnella Davis (COSMOS) serves as one of three Co-Principal Investigators. Additional Co-Principal Investigators are Kenneth Wong (Brown University) and Patricia Moyer-Packenham (Utah State University). Any opinions, findings, conclusions, and recommendations expressed in this article are those of the author(s) and do not necessarily reflect the views of the National Science Foundation.

\section{Notes}

1. The 48 MSPs, funded in the first three cohorts of awards, included 12 comprehensive MSPs (partnerships focused on K-12 mathematics, science or both), 28 targeted MSPs (partnerships focused on a narrower grade range or disciplinary focus in mathematics and/ or science) and eight institute MSPs (focused on developing mathematics and science teachers as school-based and district-based intellectual leaders and master teachers) (National Science Foundation 2007).

\section{References}

Arbaugh, F., 2003. Study groups as a form of professional development for secondary mathematics teachers. Journal of mathematics teacher education, 6 (2), 139-163.

Blank, R.K. and Alas, N.d.1., 2008. Current models for evaluating effectiveness of teacher professional development. Report No. 0736018. Washington, DC: Council of Chief State School Officers.

Blank, R.K., et al., 2006. Improving instruction through schoolwide professional development: effects of the data-on-enacted curriculum model. ERS spectrum, 24 (2), 9-23.

Bolyard, J.J. and Moyer-Packenham, P.S., 2008. A review of the literature on mathematics and science teacher quality. Peabody journal of education, 83 (4), 509-535.

Boyle, B. and Lamprianou, J., 2006. What is the point of professional development? The first three years of a longitudinal research survey. Journal of in-service education, 32 (1), $129-131$.

Briscoe, C., 1991. The dynamic interactions among beliefs, role metaphors, and teaching practices: a case study of teacher change. Science education, 75 (2), 185-199.

Clark, P.G., Moore, K.C., and Carlson, M.P., 2008. Documenting the emergence of 'speaking with meaning' as a sociomathematical norm in professional learning community discourse. Journal of mathematical behavior, 27 (4), 297-310.

Cobb, P., et al., 1991. Assessment of a problem-centered second-grade mathematics project. Journal for research in mathematics education, 22 (1), 3-29.

Cogan, L.S., Schmidt, W.H., and Wiley, D.E., 2001. Who takes what math and in which track? Using TIMSS to characterize US students' eighth-grade mathematics learning opportunities. Educational evaluation and policy analysis, 23 (4), 323-341.

Collopy, R., 2003. Curriculum materials as a professional development tool: how a mathematics textbook affected two teachers' learning. The elementary school journal, 103 (3), $287-311$.

Craig, W., 2006. The effects of professional development programs on educational outcomes in mathematics and science. Lexington, KY: University of Kentucky, Martin School of Public Policy and Administration.

Desimone, L.M., 2009. Improving impact studies of teachers' professional development: toward better conceptualizations and measures. Educational researcher, 38 (3), 181-199.

Desimone, L.M., et al., 2002. Effects of professional development on teachers' instruction: results from a three-year longitudinal study. Educational evaluation and policy analysis, 24 (2), 81-112.

Desimone, L.M., Smith, T.M., and Phillips, K.J.R., 2007. Does policy influence mathematics and science teachers' participation in professional development? Teachers college record, 109 (5), 1086-1122.

Edwards, T.G. and Hensien, S.M., 1999. Changing instructional practice through action research. Journal of mathematics teacher education, 2 (2), 187-206. 
Feger, S., Woleck, K., and Hickman, P., 2004. How to develop a coaching eye. Journal of staff development, 25 (2), 14-18.

Fennema, E., et al., 1996. A longitudinal study of learning to use children's thinking in mathematics instruction. Journal for research in mathematics education, 27 (4), 403-434.

Fernandez, C., 2002. Learning from Japanese approaches to professional development: the case of lesson study. Journal of teacher education, 53 (5), 393-405.

Fernandez, C., 2005. Lesson study: a means for elementary teachers to develop the knowledge of mathematics needed for reform-minded teaching? Mathematical thinking and learning, 7 (4), 265-289.

Garet, M.S., et al., 2001. What makes professional development effective? Results from a national sample of teachers. American educational research journal, 38 (4), 915-945.

Garet, M.S., et al., 2008. The impact of two professional development interventions on early reading instruction and achievement. Report prepared for the Institute of Education Sciences. Washington, DC: Institute of Education Sciences, NCEE 2008-4030.

Glazerman, S., et al., 2008. Impacts of comprehensive teacher induction: results from the first year of a randomized control study. Washington, DC: US Department of Education, NCEE 2009-4034.

Goldhaber, D.D. and Brewer, D.J., 2000. Does teacher certification matter? High school teacher certification status and student achievement. Educational evaluation and policy analysis, 22 (2), 129-146.

Halai, A., 1998. Mentor, mentee, and mathematics: a story of professional development. Journal of mathematics teacher education, 1 (3), 295-315.

Hanegan, N., Friden, K., and Nelson, C.R., 2009. Authentic and simulated professional development: teachers reflect what is modeled. School science and mathematics, 109 (2), 79-94.

Hiebert, J., 1999. Relationships between research and the NCTM standards. Journal for research in mathematics education, 30 (1), 3-19.

Hill, H.C. and Ball, D.L., 2004. Learning mathematics for teaching: results from California's mathematics professional development institutes. Journal for research in mathematics education, 35 (5), 330-351.

Kennedy, M.M., 1998. Form and substance in inservice teacher education. Arlington, VA: National Science Foundation, Research monograph no. 13. (ERIC Document Reproduction Service no. ED472719.)

Kennedy, M.M., 1999. Form and substance in mathematics and science professional development. NISE brief, 3 (2). (ERIC Document Reproduction Service No. ED435552.)

Klentschy, M.P., 2005. Designing professional development opportunities for teachers that foster collaboration, capacity building and reflective practice. Science educator, 14 (1), $1-8$.

Lee, H., 2004/05. Developing a professional development program model based on teachers' needs. The professional educator, 27 (1\&2), 39-49.

Lewis, C., et al., 2006. Lesson study comes of age in North America. Phi delta kappan, 88 (4), 273-281.

Lieberman, J., 2009. Reinventing teacher professional norms and identities: the role of lesson study and learning communities. Professional development in education, 35 (1), 83-99.

Loucks-Horsley, S., 1998. The role of teaching and learning in systemic reform: a focus on professional development. Science educator, 7 (1), 1-6.

Loucks-Horsley, S., et al., 1998. Designing professional development for teachers of science and mathematics. Thousand Oaks, CA: Corwin Press.

Marble, S., 2007. Inquiring into teaching: lesson study in elementary science methods. Journal of science teacher education, 18 (6), 935-953.

Marsigit. (2007). Mathematics teachers' professional development through lesson study in Indonesia. Eurasia journal of mathematics, science \& technology education, 3 (2), 141-144.

Marx, R.M., et al., 1998. Professional development of science teachers. In: B.J. Fraser and K.G. Tobin, eds. International handbook of science education. Dordrecht, The Netherlands: Kluwer, 667-680. 
Miller, D.C., Sen, A., and Malley, L.B., 2007. Comparative indicators of education in the United States and other G-8 countries: 2006. Washington, DC: National Center for Education Statistics, Institute of Education Sciences, US Department of Education, NCES 2007-006.

Moyer-Packenham, P.S., et al., 2008. The assessment of mathematics and science teacher quality. Peabody journal of education, 83 (4), 562-591.

Moyer-Packenham, P.S. and Westenskow, A., in press. Processes and pathways: how do mathematics and science partnerships measure and promote growth in teacher content knowledge? School science and mathematics.

National Center for Education Statistics, 2005. Characteristics of public school teachers' professional development activities: 1999-2000 [online]. Issue brief, August. US Department of Education. Available from: http://nces.ed.gov/pubs2005/2005030.pdf [Accessed 19 March 2007].

National Council of Teachers of Mathematics, 2000. Principles and standards for school mathematics. Reston, VA: NCTM.

National Research Council, 1996. National science education standards. Washington, DC: National Academy Press.

National Research Council, 2004. On evaluating curricular effectiveness: judging the quality of $K-12$ mathematics evaluations. Washington, DC: The National Academies Press.

National Science Foundation, 2007. MSP goals, structure and composition [online]. Available from: http://www.nsf.gov/ehr/MSP/nsf05069_3.jsp [Accessed 14 June 2007].

Nelson, T.H. and Slavit, D., 2007. Collaborative inquiry among science and mathematics teachers in the USA: professional learning experiences through cross-grade, crossdiscipline dialogue. Journal of in-service education, 33 (1), 23-39.

No Child Left Behind Act of 2001. Pub. L. No. 107-110, 115 Stat. 1425 (2002).

Oliveira, A., 2010. Developing elementary teachers' understanding of the discourse structure of inquiry-based science classrooms. International journal of science \& mathematics education, 8 (2), 247-269.

Peck, J., Barton, R., and Klump, J., 2007. Successful math and science professional development. Principal's research review: supporting the principal's data-driven decisions, 2 (1), 1-6.

Porter, A.C., et al., 2000. Does professional development change teaching practice? Results from a three-year study. Washington, DC: Department of Education, Office of the Under Secretary, Report No. DOC-2001-01. (ERIC Document Reproduction Service No. ED455227.)

Porter, A.C., et al., 2007. Alignment as a teacher variable. Applied measurement in education, 20 (1), 27-51.

Pourdavood, R.G., et al., 1999. Discourse and professional growth: processes, relationships, dilemmas, and hope. School community journal, 9 (1), 33-47.

Schmidt, W., Houang, R., and Cogan, L., 2002. A coherent curriculum: the case of mathematics. American educator, 26 (2), 10-26.

Senk, S.L., and Thompson, D.R., eds., 2003. Standards-based school mathematics curricula: what are they? What do students learn? Mahwah, NJ: Erlbaum.

Smith, T.M., Desimone, L.M., and Ueno, K., 2005. 'Highly qualified' to do what? The relationship between NCLB teacher quality mandates and the use of reform-oriented instruction in middle school mathematics. Educational evaluation and policy analysis, 27 (1), 75-109.

Smylie, M.A., 1995. Teacher learning in the workplace: implications for school reform. In: T.R. Guskey and M. Huberman, eds. Professional development in education: new paradigms and practices. New York: Teachers College Press, 92-113.

Smylie, M.A., 1996. Research on teacher leadership: assessing the state of the art. In: B.J. Biddle, T.L. Good, and I.F. Goodson, eds. International handbook of teachers and teaching. Dordrecht, The Netherlands: Kluwer, 521-592.

Snow-Gerono, J.L., 2005. Professional development in a culture of inquiry: PDS teachers identify the benefits of professional learning communities. Teaching and teacher education, 21 (3), 241-256.

Speck, M., 2002. Balanced and year-round professional development: time and learning. Catalyst for change, 32 (1), 17-19. 
Telese, J.A., 2008. Teacher professional development in mathematics and student achievement: a NAEP 2005 analysis. Paper presented at the annual meeting of the School Science and Mathematics Association, November, Raleigh, NC.

US Department of Education, 2008. Mathematics and science partnerships: summary of the fiscal year 2005 annual reports. Washington, DC: US Department of Education, Contract ED04CO0015/0003.

Wei, R.C., et al., 2009. Professional learning in the learning profession: a status report on teacher development in the United States and abroad. Oxford, OH: National Staff Development Council.

York-Barr, J. and Duke, K., 2004. What do we know about teacher leadership? Findings from two decades of scholarship. Review of educational research, 74 (3), 255-316. 